\title{
Ampullary neuroendocrine tumour - a rare cause of acute pancreatitis
}

\author{
M. Vishnukanth, S. Raviraj \\ Teaching Hospital Jaffna, Sri Lanka
}

Key words: Neuroendocrine tumour; pancreatitis; Ampulla of Vater

\section{Introduction}

Ampullary neuroendocrine tumours (ANET) are an extremely rare type of pancreatic cancer, but are a wellknown cause of pancreatitis. We report a case of an ampullary neuroendocrine tumour in a 45 year old patient who presented with acute pancreatitis and was treated with a pancreaticoduodenectomy for relief of the jaundice.

\section{Case Report}

A 45 year old non-alcoholic male, presented with epigastric pain radiating to the back and associated yellowish discolouration of the sclera. On examination, he was acutely ill with both dehydration and jaundice. Abdominal examination revealed epigastric tenderness, but there was no palpable mass.

On further work up, there was neutrophilic leukocytosis $(14,700)$, elevated liver enzymes (alanine transferase $86 \mathrm{U} / \mathrm{L}$, aspartate transferase $78 \mathrm{U} / \mathrm{L}$ ) and an elevated alkaline phosphatase $486 \mathrm{U} / \mathrm{L}$ ). Total bilirubin was $4.3 \mathrm{mg} / \mathrm{dl}$ and direct bilirubin was $2.8 \mathrm{mg} / \mathrm{dl}$. Serum amylase was $686 \mathrm{U} / \mathrm{L}$.

Ultra sound scan showed a dilated common bile duct (10.2 $\mathrm{mm})$ and a dilated pancreatic duct $(4.4 \mathrm{~mm})$. The CT scan revealed a dilated common bile duct and pancreatic duct due to a tumour of the Ampulla of Vater. The endoscopy showed a mucosal bulging at the ampullary region. The ERCP revealed a bulky major and minor ampulla probably due to a periampullary or distal common bile duct tumour. A biopsy from the bulky lesion was negative for malignant cells.

The patient underwent surgery to relieve the jaundice (Whipple's procedure/ pancreaticoduodenectomy). Histopathological assessment showed features that were highly suggestive of a neuroendocrine tumour. The resection margins and regional nodes were free of tumour cells. Pathological staging was T2 N0 Mx.

Correspondence: M. Vishnukanth

E-mail: m.vishnukanth@yahoo.com

DOI: http://doi.org/10.4038/sljs.v34i1.8229 (cc) BY

\section{Discussion}

A neuroendocrine tumour is an epithelial neoplasm with neural and endocrine origin [1]. ANET accounts for about $0.3 \%$ to $1 \%$ of all gastrointestinal neuroendocrine tumours and less than $2 \%$ of all periampullary cancers [2,3]. Immunohistochemical staining is the main diagnostic method for recognition of these tumours, and ANET stains positively with chromogranin A and synaptophysin in $92-100 \%$ cases [4].

ANET mostly presents with obstructive jaundice (53\%), nonspecific upper abdominal pain $(24 \%)$, pancreatitis $(6.0 \%)$ or weight loss $(3.6 \%)[5,6]$. ERCP should be performed in all patients with ampullary tumours. Endoscopic ultrasound is helpful in detecting the depth of invasion and the presence of lymph node metastasis. Computed tomography and octreotide scan are helpful to detect metastasis. The tumour size does not predict the possibility of distant spread in ANET, and several reports have shown ANETs of up to $5 \mathrm{~cm}$ size without evidence of any metastasis [2].

Pancreaticoduodenectomy is often the surgical option for tumours of any size with no distant spread. Extensive debulking surgery should be considered in patients with hormonal hypersecretion as even in the presence of advanced disease it carries 5 -year survival rates of up to $80 \%$. [6].

Tumour grading and distant metastasis are the most important prognostic factors. Low grade tumours have 5 and 10 year survival rates of $80 \%$ and $71 \%$ respectively, whereas high grade neuroendocrine tumours have a 5 year survival rate of $15 \%[3]$.

\section{References}

1. Selvakumar E, Rajendran S, Balachandar TG, Kannan DG, Jeswanth S, Ravichandran S. Neuroendocrine carcinoma of the Ampulla of Vater: a clinicopahologic evaluation. Hepatobiliary Pancreat Dis Int. 2008;7:422-425.

2. Mavroudis N, Rafailadis S, Syemeonidis N, Aimoniotou E, Antonopoulos E, Evgenidis $\mathrm{N}$ et al. Carcinoid tumour of the Ampula of Vater-a report of two cases. ActChirBelg 2005;105:213-216.

3. Albores-Saavedra J, Haet A, Chable-Montero F, Henson DE. Carcinoid and high grade Neuroendocrine tumour of the Ampulla of Vater- Acomperative analysis of 139 cases from surveillance, Epidemiology and End results Program-A 
population based study. ArchPathol Lab med 2010;134:1692.

4. Jaoude WA, Lau C, Suguyama G, Duncan A,. Management of Ampullary Carcinoid tumour with pancreaticiduodenectomy. JSC 2010;8:4.

5. Relles D, Back J, Witkiewicz A, Yeo CJ. Periampullary and duodenal neoplasms in Neurofibromatosis type I: two cases and updated 20 year review of the literature yielding 76 cases. $J$
GastrointestSurg 2010;14:1052-61.

http://dx.doi.org/10.1007/s11605-009-1123-0

6. Gilani N, Ramirez FC. Endoscopic resection of an ampullary carcinoid presenting with gastro intestinal bleeding : A case report and review of literature. World L Gastroenterol 2007;13:168-70.

\section{Key Point:}

- It should be emphasized that peri-ampullary or pancreatic neoplasm should be ruled out as an aetiological factor in those over 40 years presenting with acute pancreatitis for the first time, especially with no other recognizable causes.

\section{Answers to images in surgery (from page 14)}

1. Air within the renal parenchyma (clinical diagnosis: emphysematous pyelonephritis in a low lying right kidney).

2. Emphysematous pyelonephritis (EPN) is a severe form of necrotizing infection of the renal parenchyma causing gas formation within the collecting system, renal parenchyma, and/or the peri-renal tissues. It is commonly seen in women with poorly controlled diabetes mellitus. Management consists of conservative medical treatment and/or surgical management.

Medical management:

- Prompt fluid resuscitation to maintain adequate hydration.

- Empirical broad spectrum systemic antibiotics (intravenous ampicillin, gentamicin, carbepenam and metronidazole until culture sensitivities are available; vancomycin is used in patients with penicillin allergy).

- In obstructive uropathy relief of obstruction with percutaneous drainage or stent placement should be attempted. Any drainable infected collection should be drained percutaneously.

- Optimization of diabetic control.

Surgical management is indicated in the following situations:

- Failing medical management with clinical deterioration; nephrectomy is indicated.

- When percutaneous drainage of septic collections within the retroperitoneum is not available.

- When percutaneous drainage or internal stenting is not available for obstructive uropathy.

\section{References}

1. Fatima R, Jha R, Muthukrishnan J, Gude D, Nath V, Shekhar S, Narayan G, Sinha S, Mandal SN, Srinivas Rao B, Ramsubbarayudu B. Emphysematous pyelonephritis: A single center study. Indian J Nephrol. 2013 Mar-Apr; 23(2): 119-124. http://dx.doi.org/10.4103/09714065.109418

2. Sharma PK, Sharma R, Vijay MK, Tiwari P, Goel A, Kundu AK. Emphysematous pyelonephritis: Our experience with conservative management in 14 cases. Urol Ann 2013; 5:157-62. http://dx.doi.org/10.4103/0974-7796.115734 